\title{
The Role of Men in Family Planning in the Philippines: An Assessment
}

\author{
Sam Clark, Jr., ${ }^{1}$ Jonathan Flavier, ${ }^{2}$ Pilar Jimenez, ${ }^{3}$ Romeo Lee ${ }^{4}$ and Harris Solomon ${ }^{5}$ \\ ${ }^{1}$ Contractor, USAID/Ethiopia, Addis Ababa, Ethiopia \\ ${ }^{2}$ Chairperson, CMEN (Cooperative Movement for Encouraging NSV (No-Scalpel Vasectomy)), \\ Quezon City, Philippines \\ 3 Program Officer, Ford Foundation, Jakarta, Indonesia \\ ${ }^{4}$ Associate Professor, Behavioral Sciences Department, De La Salle University, Manila, Philippines \\ ${ }^{5}$ Ph.D. student, Anthropology Department, Brown University, United States
}

This article discusses the results of a USAID/Philippines-commissioned assessment carried out in 2005 that sought to identify strategies and make recommendations to develop and/or expand existing programs to include men in family planning (FP), both in support of their partners and as users of family planning methods. The assessment found substantial recent and ongoing male involvement activities in research, policy guidelines, information education communication (IEC), behavior change communication (BCC), as well as service delivery. The findings indicate that strategies to involve men in FP, while not implemented on a large scale, are feasible and warrant support. Short and long-term recommendations are made for research, policy, BCC and social mobilization, and service delivery. For research, it is vital to make greater use of existing data to assess barriers and facilitating factors for male support for and use of FP, especially the male module for the 2003 National Demographic and Health Survey. For policy and guidelines, it is crucial to designate and fund an agency with policy experience to systematically support relevant policy guidance initiatives. In IEC/BCC and social mobilization, the social acceptance project strategies (working with men in the workplace, armed services, and Muslim religious leaders) hold tremendous promise and should be expanded. Culturally familiar local and influential public figures for FP messages should be tapped along with enriching IEC handouts and posters with high quality materials that reflect local culture and language. Finally, in service delivery, it is crucial to ensure that social acceptance mobilization protocols with large agencies (such as trade unions that serve men) include planning to develop links to tangible FP services. If feasible, this should be combined with efforts to adapt community based management information systems to identify unmet need among men within the membership of these agencies.

KEYWORDS: Filipino men, family planning, male involvement, reproductive health, contraceptive use

Current use of effective family planning (FP) methods, as reported by women in the 2003 National Demographic Health Survey (NDHS), remains disappointingly low despite three decades of FP program effort. Use of modern methods is a modest 33.4 percent (National Statistics Office [NSO] Opinion Research Corporation [ORC] Macro, 2004). An estimated one-fourth of women 
with a demand for FP are not using contraception. Rather than decline over time, the percentage of births reported as unwanted has increased from 18 percent in 1998 to 20 percent in 2003. On average, women's total wanted fertility (2.5) is exceeded by actual total fertility (3.5) by one child, a discrepancy of 40 percent. In this alarming situation, male condom and male sterilization accounted for only 2.0 percentage points of FP use in 2003.

It is widely acknowledged that the Philippine FP program has focused almost exclusively on women and may have missed opportunities to effectively involve men to address these challenges (Lee \& Dodson, 1998). Research findings from the Philippines show that men are influential gatekeepers for FP acceptance in the household and are an important client group for FP program efforts (Casterline, Perez \& Biddlecom; 1997; Perez \& Palmore, 1997; Perez, 2000). Due in part to the lack of progress in the Philippine FP program, USAID programs have intensified efforts to include men in FP advocacy and services (Management Sciences for Health, 2003).

For more than a decade, there have been increased efforts to include men in FP programs. This is the result of many factors, including the 1994 International Conference on Population and Development (ICPD) Plan of Action, the global HIV/AIDS pandemic, and high quality quantitative data on men from the Demographic and Health Surveys (Ezeh, Seroussi, \& Raggers, 1996). There is evidence that working with men (especially with women in a couple approach) in FP and related reproductive health $(\mathrm{RH})$ areas can result in improved health outcomes (Becker, 1996). USAID's Interagency Gender Working Group (IGWG) has developed resources that document health program justifications for including men in FP (Interagency Gender Working Group [IGWG]Orientation Guide, 2002) as well as compelling program examples (IGWG Implementation Guide, 2005). Studies show that involving men can have significant benefits to FP programs for contraceptive acceptance, continuation, client satisfaction and efficacy (Fisek \& Sumbuloglu, 1978; Bhalerao, Galwankar, Kowli, Kumar, \& Chaturvedi, 1984; Terefe \& Larson, 1993; Wang, 1998; Amatya, Akhter, \& McMahan, 1994). Given these encouraging findings, the Philippine FP program may benefit from the implementation of practical and culturally rooted strategies to involve men in FP.

Three important caveats should be considered in including men in FP (AVSC, 1998; Clark, Brunborg, Rye, Svanemyr, \& Austveg, 1999). First, men's participation in FP should be "constructive;" that is, it should always protect women's interests and not reinforce traditions of male dominance. Second, involving men may require added expense and may mean competition for scarce resources. Programs to include men in FP need to add rather than subtract resources from existing programs for women (AVSC, 1998). Third, efforts to involve men must be cost-efficient in terms of better outcomes in order to justify additional funds.

This assessment of men and FP is based on a gender-equity framework that is the result of over 10 years of gender policy dialog, from the 1994 ICPD to recent work by the USAID IGWG (IGWG, 2002; IGWG 2005). The assessment is informed by important gender frameworks within the Philippines. These include the updated Gender and Development Guidelines (NEDA, 2003), a collaboration between EngenderHealth and the Philippines NGO Council (PNGOC) (PNGOC, 2002); the United Nations Population Fund (UNFPA) 5th country program (UNFPA, 2000); and a recent examination of gender issues related to male involvement in reproductive health in the Philippines (Badiane, 2005).

Building on previous male involvement approaches (Cohen \& Burger, 2000), this framework views men as equal partners of women but acknowledges that "gender inequities influence fertility behavior" (Badiane, 2005). The framework emphasizes a partnership between men and women in decision making, 


\section{Figure 1.}

\section{Continuum of Approaches for Gender Integration*}

\begin{tabular}{|c|c|c|}
\hline Gender Exploitative & Gender Accommodating & Gender Transformative \\
\hline $\begin{array}{l}\text { Programs that ...exploit } \\
\text { gender inequities and } \\
\text { stereotypes in pursuit of } \\
\text { project outcome. Often } \\
\text { harmful in long-term and can } \\
\text { undermine program objectives. }\end{array}$ & $\begin{array}{l}\text {....accommodate gender } \\
\text { differences to achieve project } \\
\text { objectives. May make fulfilling } \\
\text { gender roles easier but does } \\
\text { not attempt to reduce gender } \\
\text { inequality. }\end{array}$ & $\begin{array}{l}\text {....seek to transform gender } \\
\text { relations to promote equity } \\
\text { and achieve program } \\
\text { objectives by encouraging } \\
\text { critical awareness of gender } \\
\text { roles and promoting improved } \\
\text { women's status. }\end{array}$ \\
\hline $\begin{array}{l}\text { Example: Condom social } \\
\text { marketing campaigns that use } \\
\text { aggressive or violent imagery } \\
\text { to reinforce male decision- } \\
\text { making power and control. }\end{array}$ & $\begin{array}{l}\text { Example: Projects that take } \\
\text { services to women who have } \\
\text { limited social mobility; } \\
\text { doorstep distribution of oral } \\
\text { contraceptives (OCs) in } \\
\text { Muslim society where women } \\
\text { are in seclusion. }\end{array}$ & $\begin{array}{l}\text { Example: Programs that work } \\
\text { with young men and young } \\
\text { women to challenge rigid } \\
\text { gender roles. }\end{array}$ \\
\hline
\end{tabular}

*Adapted from USAID IGWG Presentation, 2005.

and encourages human rights for both men and women. It also proposes an educational approach to sensitize men about male and female gender roles and their consequences (Badiane, 2005; Cohen \& Burger, 2000; Greene, 2003; Greene \& Biddlecom, 2000; Greene, Mehta, Pulerwitz, Wulf, Bankole, \& Singh, 2004).

It is important to clarify how this framework is applied with concrete examples, as shown in Figure 1. Approaches to FP activities to involve men can be allocated into three categories: gender exploitative, gender accommodating, and gender transformative. Efforts to involve men should avoid the first two and attempt to use a gender transformative approach. Work by the Population Council Horizons program has shown that programs that help young men reflect on their gender identity and change gender norms can improve knowledge, attitudes and behaviors related to FP and sexually transmitted infections (STIs) (Barker 2004; Pulerwitz, Barker, \& Segundo, 2004).

\section{OBJECTIVES AND METHODS}

The assessment had four objectives:

1. Conduct an analysis of studies and related literature on Filipino men and FP in the Philippines;

2. Review current program policies and guidelines and determine how they enhance or discourage male participation in FP;

3. Assess attempts to consider men in the design and implementation of family planning programs; and

4. Recommend strategies to encourage and strengthen male participation in family planning communication and service delivery activities.

\section{METHODS}

In-country work over a three-week period in February 2005 included extensive meetings with 
USAID, interviews with local staff of selected USAID-supported cooperating agencies, representatives from selected donor agencies, government and non-government organizations, the academe and other local partners and experts. A review and in-depth analysis was conducted of relevant studies including NDHS reports and annual FP surveys, as well as recent unpublished qualitative and quantitative research. Field trips were taken for interviews and focus group discussions (FGDs) with various stakeholders, male and female groups including female and male FP service providers, men in uniform, Moslem religious leaders, Standard Days Method (SDM) and non-scalpel vasectomy acceptors. Efforts were made to ensure both men and women clients were interviewed. FGD participants included 13 women and 15 men; approximately 65 men and 71 women took part in various information gathering meetings and interviews during the course of the assessment.

\section{BRIEF HISTORY OF MALE INVOLVEMENT STRATEGIES IN THE PHILIPPINE FP PROGRAM}

The Philippines officially launched its population and national FP program in the early 1970s, directing private and public sectors to promote contraceptive methods, including male and female sterilization, to Filipino couples of reproductive age. In its early years of implementation, the program recognized the role of men in decision making in the family and in the larger society. In the late 1970s, the program adopted a male involvement strategy with men as community-based counselors and motivators, and advocates to promote FP methods. At this time, hundreds, perhaps thousands, of Filipino men accepted vasectomy (Despabiladeras, undated). From the mid-1980s through the mid-1990s, male involvement, as part of an overall effort to increase contraceptive use in the country, was sidelined by a host of factors: religious opposition, social, economic and political upheavals, and natural disasters. The Philippines revived the strategy of male involvement in the mid-90s bolstered by the 1994 ICPD platform seeking to improve women's status and health.

The re-emergence of male involvement, aligned with a gender equity framework, was linked to three developments: an emphasis on a comprehensive reproductive health approach, advocacy by NGOs, and greater autonomy for women. First, male involvement was tied to a range of issues under the heading of reproductive health: STIs, maternal and child health $(\mathrm{MCH})$, prevention and management of abortion, gender violence, prostate and testicular cancer, adolescent reproductive health, and infertility as subsumed under the broad term 'reproductive health'. In practice, public and private efforts have mainly involved men in the context STIs and HIV/AIDS, FP, and gender violence. The health program of the Provincial Government of Nueva Vizcaya was an important exception. The province established a working committee at various administrative levels (provincial, municipal or barangay) to address all of the RH elements mentioned above.

Second, male involvement has been led by nongovernmental and funding organizations whose base and foothold in the country's health matters and activities have considerably grown since the 1970s. Examples include the Family Planning Organization of the Philippines (FPOP), WellFamily Midwife Clinics, FriendlyCare; international FP support organizations like the Darmendra Kumar Tyagi (DKT), Management Sciences for Health (MSH), and Marie Stopes; and a network of NSV (non-surgical vasectomy) service providers.

Finally, the revival of the strategy to involve men occurred at a time when women's entry into the formal labor force encouraged gender equity in FP. Women, conventionally confined within the household, took on an added role as economic providers. From 1991 to 2004, locally employed female workers increased by 62.2 percent and more women than men are now working overseas (69\% versus $31 \%)$. 
Given the revitalized efforts to encourage men's participation, some progress has been documented. A 1998 national study was undertaken to examine the status, challenges and prospects of male involvement in women's health initiatives (Lee \& Dodson, 1998). A series of seminars and workshops were held, and culminated in the development of men's reproductive health strategic program framework (PNGOC, 2002; DOH, 2002). A number of small-scale and larger province-wide activities in research, communications, and service delivery have been initiated with support from the UNFPA and other organizations. The Commission on Population (POPCOM) has identified 28 projects related to men and FP throughout the Philippines since 2000. While the POPCOM data do not fully capture all work to involve men in FP throughout the Philippines (it omits male involvement in FP projects by FP Organization of the Philippines (FPOP), the Department of Health (DOH)FP program, DKT, etc.) it documents a great deal of activity (the 28 projects are outlined in Annex D of the March 2005 USAID POPTECH Report) (Clark et al., March 2005).

The above cited efforts to encourage male involvement have tended to be sporadic, however. They do not part of a unified, national and comprehensive program designed to use the involvement of men to improve the acceptance, efficacy, and continuation of FP method use. The programs to involve men in FP have not improved the contraceptive method mix nationally. Over the last decade, condom use has increased by less than one percentage point, and the overall proportion of male methods (condom, vasectomy and withdrawal) has remained fixed at about 20 percent of methods used by married women.

\section{RESULTS}

\section{A. Studies and literature on Filipino males in FP}

While limited, the Philippines has high-quality empirical information and literature, both published and unpublished, on the subject of men in FP. Data have come from large-scale quantitative surveys (NDHS, FPS, Cebu Longitudinal Health and Nutrition Study, Young Adult Fertility and Sexuality Survey, and Men's Study on Sexuality and AIDS) and from qualitative studies (FGDs and key informant interviews) that involve men, along with women, from various geographic locations across the country (more urban than rural). While much useful NDHS data for men are presented in the October 2004 National Statistics Office (NSO) report from the 2003 NDHS Male Module, a large amount of important data for men from the 2003 national survey remains to be analyzed (NSO ORC Macro, 2004). This is an important research priority.

On the whole, the most commonly examined topics have been men's sexual behavior, and FP knowledge, attitudes and practices. Based on a landmark study of 780 matched couples in rural and urban Philippines, researchers concluded that "men's views need to be taken seriously in the development of interventions to reduce unmet need in the Philippines" (Casterline et al., 1997). In their study, almost one-fifth of unmet need among the Filipino couples could be attributed to husbands' negative perceptions (Casterline et al., 1997).

Major findings from recent quantitative surveys are as follows.

- Sexual behavior: Based on a 1999 survey of men in three urban areas, most Filipino men aged 15-44 have had sex (84.1 percent) beginning on average at the age of 18.8 (Jimenez \& Lee, 2001). Most of these urban men (87 percent) reported having only one sexual partner (their spouse) in the past year, and only 7.1 percent have intercourse with a sex worker. Nationally representative data for men age 15-49 in 2003 found that only 1.9 percent of men reported having intercourse with a sex worker in the past 12 months (NSO ORC Marco, 2004).

- Attitudes toward FP: Filipino men are well aware and are in favor of FP. As of 2003 in the NDHS, $97 \%$ of men were aware of 
one or more modern methods (NSO ORC Macro, 2004). A 1993 survey in the Philippines found that men and women have similar views of contraception: 72 percent of husbands and 77 percent of wives strongly approved of contraception (Casterline et al., 1997) Among married women who are not using FP, husband opposition accounts for less than $4 \%$ or reasons for non-use, less than half the level of opposition to FP among the women themselves (9\%) (NSO ORC Macro, 2004).

- Use of FP: Over the last decade, male methods have accounted for about 20 percent of methods used by women. As reported by currently married women in 2003, negligible numbers of adult married men are currently using effective male FP methods: only 0.1 percent was currently using male sterilization and 1.9 percent used condoms (NSO ORC Macro, 2004). The most common male method in use is withdrawal at $8.2 \%$. There is no evidence, however, that women are clamoring to use male methods. Male methods were the least preferred future methods among currently married women who intend to use a method in the future. A 2002 nationally representative youth survey indicates that male method use, especially condoms, may be greater among younger men, condoms accounting for $40 \%$ of contraception use at first intercourse (Raymundo \& Cruz, 2004). In the 2002 Cebu Longitudinal Nutrition and Health Survey of young men age 17-19 in Cebu, over 90\% had heard of FP; over half of these youth who had sexual experience reported ever use of FP.

- Gender roles: There was very close agreement between men and women concerning the right of a woman to refuse sex if her husband has a sexually transmitted infection (STI) (94.7 percent of women versus 94.1 percent of men). Remarkably, 97 percent of men agreed that the wife had a right either to refuse sex or to propose that her husband use a condom if her husband has an STI (NSO ORC Macro, 2004).

The USAID Assessment Team collected additional qualitative data by conducting FGDs among FP acceptors of NSV (two FGDs), Standard Days Method (SDM) clients and their wives (one FGD), men in uniform (MIU) (one FGD), and key informants' interviews among service providers. While not representative and somewhat anecdotal in nature, results from FGDs conducted in February 2005 contained recurring economic themes justifying FP use, such as aspirations for the needs of their children, because of economic hard times and unstable jobs, and wanting to send their children to school. Other reasons for using FP included it being an expression of love for their wives and children, concern for the risks of pregnancy, partners' encouragement, and a practice learned from a man's parents. Reasons for not using FP ranged from wife is already using a method, to wanting to have another child, to lack of interest. Vasectomy was not accepted by some men due to fear of loss of sexual performance, equation with castration, leading to a change in sexual orientation, impact on ability to work, and potential lost days of work to undergo the procedure. Men endorsed vasectomy because the procedure is free, positive testimony from friends, safety, prior method failures, concern about risk of female sterilization for wives, and because of effective counseling from health workers. In some of the FGDs there was reference to men not feeling welcomed to FP service sites as a reason for not using FP.

In summary, Filipino men, adult and young alike, have extensive knowledge and favorable attitudes related to FP. Very few adult men, unlike a substantial number of young males, report the use of effective male contraceptives. Reasons for using and not using methods have been shown to be largely due to economic, familial and genderrelated factors. Reasons pertaining to service 
provision, although cited as a contributing factor, have yet to be investigated for their role in facilitating and hindering method use. Especially in the case of the available EDHS data, much of which has yet to be analyzed, research has not been effectively utilized to broaden men's involvement in FP in the context of their own use of the methods or in supporting their female partners' use of the methods.

\section{B. Current program and operational policies and guidelines}

Policies across sectors on national and subnational levels may offer prospects for increased men's involvement in FP. The assessment identified existing or planned policies, which, if effectively implemented, are likely to encourage men's involvement.

The assessment revealed both informal and formal policy elements that facilitate and/or inhibit male involvement. Informal policies here refer to unwritten or casual protocols. Examples on the national level include high-ranking Filipino government officials' reluctance to support FP, thus, limiting potential opportunities for male involvement. More local informal policies are illustrated by a mayoral dictum in Valencia City, Bukidnon, declaring that PhilHealth benefits, including full reimbursement for no scalpel vasectomy, are restricted to couples who bear only two or fewer children. Informal policies related to male involvement affect women as well. In Cebu City, a metropolitan FP clinic implements an unwritten service delivery protocol, unwritten but often implemented, whereby wives of NSV acceptors were encouraged to accept the injection of one dose of DMPA in order to eliminate the "uncertainty" of men's condom use in the period immediately following NSV.

The scope of relevant formal program and operational policies extends from national bills calling for equal inputs from men and women in FP, to military circulars emphasizing men's constructive roles in FP.
- Legislation/Bills: Numerous bills related to reproductive health and FP have been submitted for consideration by the Philippine House of Representatives and the Senate. Notably, none explicitly champion men's involvement in FP, despite provisions on "couple" or "shared" responsibility in reproductive health.

- Policies within the Department of Health (DOH): The Philippine NGO Council on Population, Health and Welfare (PNGOC) strategic program framework and Men and Reproductive Health Policy Statement were submitted to the DOH Center for Family and Environmental Health, but no administrative action has been taken to approve the statement. The DOH reported that male involvement is to be maximized in DOH FP protocols. The DOH intends to pursue men's support for their partners' use of FP, as well as the use of male methods (the "male involvement in RH" perspective), rather than pursuing activities related to men's infertility or STI-related needs (the "male RH" perspective).

- The DOH is mandated to retain five percent of the operating expenses of its hospitals for "health promotion", including voluntary sterilization. The DOH could strategically use these funds towards higher male method acceptance.

- The DOH can publicly support a greater role for men in FP. Previously, the DOH provided free space on media channels for IEC campaigns, some of which address FP. Free support for media has not been offered by the current administration. Media campaigns have been designed for all FP methods, including special spots for condoms and vasectomy, but DOH's current policy and limited funding restricts the dissemination of innovative media strategies to promote men in FP (Interview with Jomar Fleras, Reachout International Foundation, February 9, 2005). Similarly, the Philippines Advertising Board's 
discomfort with public FP messages in the media has restricted condom social marketing efforts when condoms are positioned as a pregnancy- prevention measure (Interview with Benny Lapitan, DKT, February 9, 2005).

- The DOH's MCH Guidelines encourage partner as well as family and community involvement in prenatal and postnatal services Revised guidelines further support men's involvement in maternal and child health care and explicitly make links to FP opportunities during the prenatal period. Operations research has demonstrated how male involvement in their partners' prenatal care increased couples' discussion and use of contraception and improved knowledge about pregnancy and FP (FRONTIERS Project, 2004).

- Insurance Coverage: The Philippines Health Insurance Corporation (PhilHealth) offers full reimbursement for NSV procedures performed in "accredited" facilities. An increase in the facilities that are granted such accreditation can expand PhilHealth's coverage for NSV. Accreditation requirements for NSV were made less restrictive in a March 2005 $\mathrm{DOH}$ revision of licensing criteria. The challenge is develop procedures and guidelines that will expedite accreditation based on the less stringent $\mathrm{DOH}$ licensing requirements.

- Pre-Marital Counseling: National premarital counseling, instituted by Presidential Decree 965, is required for a marriage license recognized by the civil registrar. The counseling sessions are supposed to include human sexuality, MCH, FP, HIV/AIDS, and responsible parenthood. FP is introduced as "a shared decision between husband and wife." However, opportunities for men's involvement are not explicitly highlighted.

- Labor Policies: Under Article 134 of the Labor Code, companies employing 200 of more individuals are required to provide free FP services. This policy is an excellent opportunity to reach men where they are, i.e., at the workplace. The Trade Union Congress of the Philippines (TUCP) has expanded use of this code as part of collective bargaining agreements (CBAs) with great success. As of 2003, 68.8 percent of the 324 CBAs monitored by the Department of Labor and Employment included provisions on FP (Jaymalin, 2005). Measures must be implemented, however, to ensure that men actually receive services covered under the provisions of the Article.

- Military: Adraft circular that will implement a FP program in the Department of National Defense (DND) and its bureaus, agencies, and offices is currently awaiting approval of the Chief of Staff of the Armed Forces of the Philippines. The proposed FP program will include awareness-raising about FP methods among members of the defense establishment, training of service providers and counselors, and provision of FP commodities.

To summarize this section, gender-related clauses in government policies across sectors offer opportunities to highlight the utility of men's involvement in FP. A particularly strong example is the possible DOH approval of the Men's RH Framework. PhilHealth has shown support for NSV and is a key player in efforts to increase access to the procedure in accredited facilities. Innovative policies on male involvement in FP exist beyond the scope of the DOH, e.g., policies for men in the military and in the workforce.

\section{Information-Education-Communication(IEC)/ Behavior Change Communication (BCC) and Social Mobilization Strategies for Male Involvement in FP}

Based on a survey of materials and programs, the assessment identified themes of selected IEC/ 
BCC and Social Mobilization materials designed to encourage acceptance and use of FP methods by men and their partners. The assessment identified various IEC/BCC and Social Mobilization strategies used to facilitate the involvement of men and their partners in FP. While some of these strategies are quite promising, others need to be reconsidered in light of important gender issues.

\section{Types and themes of selected materials}

The assessment team gathered around 40 items, mainly about men and FP, during visits to public and private agencies in the country. Over half of these materials are posters/flyers; a few were training modules, books/monographs, comic books, and TV and radio ads. Majority of these materials were developed in Metro Manila. In Mindanao, the team noted that a vasectomy flyer, which was printed almost a decade ago, was being duplicated by some health facilities providing health services for men. The key themes of these IEC tools to hasten the acceptance and use of FP methods by men and their partners are:

- Men's health (e.g., use of condoms to avoid diseases, description of NSV, proper use of condom);

- Men's responsibility for their own actions (e.g., a young man encouraging other men to know more about STD/AIDS and FP by visiting the health center);

- Men of all ages actively supporting their partners (e.g., a young couple who are both movie stars endorsing the SDM; the poster of a physician testifying to the positive effects of NSV for himself, his children and wife; a TV ad of a young couple endorsing condoms; radio ads with male and female voices encouraging the public to use natural and modern FP methods). Most of the IEC materials fall under the third key theme.

The assessment team identified two sets of highquality gender-equitable training tools that promote male involvement: the training module for couples developed for the assets-based social mobilization program of Save the Children in Iloilo and the UNFPA training modules for RH (UNFPA, 2000). These materials use participatory training approaches and are very inclusive of men. Save the Children's module covers a discussion of human anatomy, the couple's perception of FP and different risk groups, population and environment links with FP, FP methods, testimony of a satisfied couple on FP, a couple's decision on a FP action card, and training evaluation.

\section{Illustrative Strategies}

Mass mobilization in the Workplace:

A key strategy to involving men and their partners in FP is to reach a large number of men where they regularly gather in the workplace. The Social Acceptance Project-FP (TSAP-FP) develops partnerships with influential male leaders in the workplace, and provides training and information regarding population, development, poverty and related issues, health and FP services, and modern FP methods. TSAP-FP programs solicit the program workers' own perspectives and plans to reach out to other men and their partners to increase the use FP methods. Materials for effective communication are likewise provided to enhance advocacy skills to reach the target sectors.

Labor Unions and Confederations: TSAP-FP is reaching a large number of men where they regularly gather in the workplace. Funded by USAID since August 2002, TSAP-FP has engaged the National Confederation of Tricycle Operators and Drivers Association of the Philippines (NACTODAP), and the National Defense College of the Philippines (NDCP) to facilitate the acceptance and use of FP methods among men and their partners in their respective work environment. NACTODAP has collaborated with TSAP-FP in engaging about 100 presidents of its local associations (numbering more than 2,000 all over the country) to become peer motivators in their respective associations. The five-day orientation training provided by TSAP-FP in February 2004 included the following topics: macro 
picture of the relationships between and among population, development, and poverty; the country's health situation; the health of tricycle operators and drivers; the various FP methods; and FP communication techniques. The peer motivators' messages emphasize that men make important contributions to FP; that they are partners in FP promotion by discussing it with others, by supporting their partners' use of a method, and by using FP methods themselves.

The Trade Union Congress of the Philippines (TUCP) is a 30-year old organization that launched a program in 1998 to target men's health for the 22 out of its 35 million worker membership (as of January 2004) throughout the country. Supported in part by UNFPA, TUCP utilizes a comprehensive reproductive health approach to men and FP. Many men work in hazardous jobs and are often victims of accidents. Their "macho" psyche makes them vulnerable to occupation and $\mathrm{RH}$ hazards. Meanwhile, there are few programs that address their unique health needs (TUCP, 2005).

TUCP successfully negotiated with employers in its collective bargaining for a subsidy of P500 per month for each covered worker for the union's RH program. This amount is not limited to female methods and Pap smears; service providers in 10 family welfare clinics serving union members are trained on gender-responsive planning and services and are updated in contraceptive technology and quality care. To encourage men's participation in the program, TUCP developed posters that depict men as responsible partners of women. Weekend seminars for young men use a training module that focuses on shared and active involvement, gender sensitivity, FP methods, STIs and other related health issues. The men are also informed about vasectomy as a permanent method and as an option for those who reached their fertility goals. The TUCP has also trained a network of male peer educators on FP/RH. Despite positive feedback about the foregoing strategies and activities, the union noted a number of issues. It reported that men are "still tied to their time sheets and cannot devote their time to FP/RH activities even as they feel the need to."
Men in Uniform (MIU): The assessment conducted interviews and a FGD discussion with Kidapawan City's MIU, who have been engaged in RH and FP promotion in their workplaces. The recent draft circular institutionalizing FP in the armed service is a major development for this group. The group feels it is important for men in the service to learn about FP in order to dispel the common notion that FP is a female concern and that the use of an FP method would diminish their manhood. The MIU respondents see the need to address incorrect information about modern FP methods (e.g., they are considered abortifacients) that is being circulated by the Catholic Church. The MIU respondents also see the need for male providers at the health centers because many of the women health workers, currently in the centers, are insensitive to their FP needs. They reported that they are often heckled as "womanizers" by these health providers when they would ask for condoms. Based on qualitative interviews and the FGD, the MIU participants suggested a variety of locally oriented communication strategies. There should be more pulong-pulong (dialogue) on FP with barangay tanod (village peace and order officers), local leaders who are mostly men in the various barangays. Updated flyers are needed on FP in the local language. There should be posters with messages/slogans showing MIU as models who are introducing RH/FP to the barangay. The radio program such as the Pulisyang Katawhan (Police of the People) should include a discussion on FP, e.g., policeman encouraging his partner/wife to use an FP method. TV program advertisements should portray MIU giving testimonies about FP. There should be health services with male health providers and Barangay Health Workers (BHWs) and even a men's desk for FP, similar to the women's desk for violence against women and children (VAWC), so they will not be embarrassed or heckled whenever they would ask for FP advice and condoms

Outreach to Religious leadership:

TSAP-FP has worked successfully since 2002 with Muslim Religious Leaders (MRLs) of the 
Autonomous Region of Muslim Mindanao (ARMM), which has relatively low contraceptive prevalence. The TSAP-FP project cooperated with MRLs in crafting a national fatwa to surmount the cultural belief that FP is not allowed in Islam and the widely-shared notion that FP is a strategy of the government and its allies to decimate the small Muslim population in the country. Highlyrespected male and female Muslim religious leaders and health service providers disseminate the religious and health aspects of the fatwa in the region. These influentials have also developed culturally-appropriate orientation materials (e.g., the marriage counseling guide for the ulama and the orientation guide for MRLs). During assessment interviews, male and female Muslim leaders cited the need for additional complementing strategies to quickly gain the attention of Muslims in the ARMM, which is comprised of several large provinces. Suggestions included stand-alone radio/ TV messages oriented to Muslims conveying that FP is allowed in Islam and can enhance sexual relations with one's partner; posters or billboards showing Muslim influentials (with large photos) endorsing the above messages and placed in and outside of health centers; and assigning male staff to health centers (If this is not possible, female midwives must be made sensitive to health needs of men). This last suggestion was shared by Muslim women respondents, who are themselves health providers.

\section{Social Marketing/Mass Media:}

The DKT Philippines is a 15 -year old NGO that has a two-pronged aim of improving public health "through pro-active social marketing interventions that enhance continued effective FP practices as well as contain the spread of STDs and HIV/AIDS." It promotes a variety of condoms to varying social classes of sexually-active men and women between the ages of 18-35 and markets oral contraceptive pills and injectables to young couples between the ages of 18-30.

DKT strategies span the range of the gender integration continuum. In the late 1990s, it had a series of TV advertisements of young couples endorsing condoms. In recent years, it had a flyer showing a popular radio announcer and his son and other wholesome-looking members of his family and friends to market condoms. In marketing the injectable, a photo shows the face of a happy woman with a smiling man behind her. A new TV ad shows a popular TV star with her partner and family in the background endorsing the pill. While the foregoing ads may be assessed as gender equitable, the commercial used to promote condoms for safer sex and FP are not as gender sensitive. For example, flyers, table posters, and packages of condoms have depicted homelylooking comedians alongside very attractive skimpy-dressed young women proclaiming that they are responsible and reliable men. These macho images are reportedly appealing to men because the material portrayed seems "culturally appropriate." The 2005 calendar on Trust condoms shows young attractive calendar girls with scanty clothing. More gender-equitable IEC strategies could achieve condom sales goals and simultaneously challenge traditional norms of masculinity that may inhibit men's positive involvement in FP.

\section{Community-Based Strategies:}

With funds from the Packard Foundation, Save the Children implements a community-based program in Iloilo linking FP with other community concerns like environment, family health and child survival (Save the Children, 2003). Its key IEC strategy is social mobilization well before any attempt to introduce FP. At least six months of intense effort is made with the community on other development issues before FP is even discussed.

The assets-based social mobilization forms the basis for FP intervention with couple motivators. The couple approach uses one couple for every 30 households in the villages. "Go sitio" means that they avoid working with barangay health center (BHC) leaders, trying instead to work with the marginalized population. Trusted local users motivate others. It was found that the male community-based development workers are just as effective as their female counterparts. A marked increase in the number of FP acceptors was noted in the 
beneficiary communities served by male workers in 2001-02 (Save the Children, 2003). Save the Children will soon pilot a similar assets-based social strategy with a focus on NSV. While staff intensive, this promises to be a very effective approach.

The Integrated Population and Costal Resources Management (IPOPCORM) initiative is a similar effort to Save the Children, i.e., it is concerned with $\mathrm{RH}$ and the environment using indepth and long-term social mobilization approaches. The program is managed by the PATH Foundation Philippines, Inc. and covers 105 coastal barangays in 18 municipalities, spanning nine priority marine conservation areas. IPOPCORM's program works to simultaneously build local capacity for coastal resource management and improve reproductive health outcomes in these areas through expanding FP services and focusing on the prevention of AIDS and other sexually transmitted diseases. The program has a strong men and FP approach, including training male community outreach workers. The program is highly notable for its carefully designed methods for collection of baseline and follow-up data to assess key male respondent indicators, including reported condom use at last intercourse. Results from the follow-up survey should be an important resource to assess the role of men in FP. IPOPCORM has achieved a ten-fold increase in access to FP services in the area in which it works, establishing over 800 service points in the program's coastal communities (Population Reference Bureau, 2004).

The Nueva Vizcaya Male Involvement in RH project (in the province with the highest CPR in the Philippines, 67 percent) was initiated by a municipal health officer (MHO) who sought the participation of elected local barangay officials as role models within UNFPA's comprehensive RH program. The project, which started in 2003, identified the male groups and their political structure, in particular the barangay and its purok leaders where RH could be introduced. The target groups of this initiative are the husbands of married women and male adolescents. The project aimed to involve the men on various aspects addressed by the UNFPA comprehensive RH health training modules, including FP, gender and sexuality, STD/ HIV/AIDS, male RH, adolescent RH, and violence against women (UNFPA, 2000). Strategies were designed to raise the level of men's involvement and by organizing and training them as peer motivators and counselors, FP consumers, and as sources of FP support for their partners/wives. The MHO conducted a series of trainings using most of the UNFPA RH training modules. The MHO reported that these training activities were so successful that attendance grew to include both men and their partners and older children. The participants became trainers themselves and they chose topics that they enjoyed to teach and they extended their training to other municipalities. Members of the Nueva Viscaya Men and RH Task Force who were interviewed said they are supportive of FP and some of their members have had NSV. Although the men have considerable training in $\mathrm{RH}$ and are sensitized to gender issues and are more likely to practice FP, it was noted that they had little or no data to demonstrate any impact on FP use. There may be advantages for a comprehensive multi issue $\mathrm{RH}$ approach versus a narrow approach that engages men on just FP issues. The MHO felt that the comprehensive approach appears to captivate men's interest rather than the narrow focus on FP because they are also interested in sex and STIs, MCH, VAWC, and adolescent reproductive health.

The Institute for Reproductive Health (IRH) developed the Standard Days Method (SDM) Couple strategy. The IRH introduced the SDM of natural family planning to the Kaanib (farmers' cooperative) in Malaybalay, Bukidnon in 2001. IRH developed the strategy working in partnership with the local nurse in charge of FP by identifying couples who were not users of any method or were using a calendar method with a menstrual cycle of 26 to 32 days. The couples were identified using a community based management information system (CBMIS), which is described in more detail below. The strategy ensures acceptance by bringing together the husband and wife so that the method 
could be carefully explained to them. The project director recommended the following communication strategies: 1) the experiences of successful couple users should be publicized and shared in various public gatherings such as the barangay summit and public hearings for bills and other matters; 2) messages through radio ads and drama would be another venue for successful users to dramatize their experiences; 3) billboards in strategic locations showing a wholesome popular couple (e.g. movie star couple) makes it easier for the public to recall family planning messages.

In summary, the review of IEC/BCC and social mobilization strategies identified the following promising approaches and practical suggestions for improving communication strategies to encourage men in FP:

- Orient men on FP methods jointly with their partners/wives. This sustains method use when men and women are able to communicate with their partners effectively (e.g., SDM users).

- Engage couple motivators to provide FP orientation to prospective male acceptors and their partners (e.g., Save the Children, assets-based social mobilization, SDM);

- Have male peers and superiors promote FP in the workplace and in their communities (e.g., Trade Union Congress of the Philippines (TUCP), National Confederation of Tricycle Operators and Drivers Association of the Philippines (NACTODAP), Save the Children);

- Provide orientation training to male health providers and respected leaders (e.g., MRLs, MIU).

- Design media promotion materials (e.g., posters, flyers, billboards, radio and television programs) to include subjects from their own ethnic communities (MRLs) or occupational grouping (MIU), or admired movie stars (SDM) and respected influentials (Dr. Flavier and NSV);

- Design IEC/BCC to address deep-seated cultural beliefs and biases (e.g., MRLs and the fatwa);
- Integrate FP into the clients' basic concerns in life such as environment and livelihood (e.g., Save the Children and IPOPCORM);

- Train health providers, both males and females, to be more sensitive to men's FP and other health needs; (e.g., TUCP, MIU, MRLs);

\section{Service Delivery Strategies to Reach Men}

The assessment considered a variety of service delivery strategies to involve men in FP. In addition it gave special attention to promising strategies for providing NSV services. The following observations came out from discussions with service providers and stakeholders as well as activities of NSV clients and couples using SDM natural family planning.

In considering FP service delivery for men, it must be kept in mind that FP service needs for men vary at different life stages (USAID, 2005):

- Adolescents need information and services, including education on fertility awareness and delaying first sexual activity, and advice on the proper use of condoms and other modern contraceptives.

- Men at the prime of reproductive ages need information on their role in facilitating their wives' or partners' practice of FP, promoting the value of condoms and NFP/ SDM in married life, and consideration of NSV or BTL (bilateral tubal ligation) when they have completed their family size.

- Older persons may need to use NSV and other longer-term FP methods to limit family size.

The main challenge to encourage male involvement in FP is to get them into action, directly involved in service delivery. This requires effective ways to reach out to men, in their homes, in their communities or in their workplace. The assessment team found promising approaches for providing FP services for men and/or helping men to be more supportive of women using FP. These approaches 
can be placed in three main categories: 1) CBMIS (community-based management information system) at the local health unit level as described below in Bago City and Bukidnon Province; 2) Social acceptance mobilization approaches that endorse a gender equitable model of men and FP (TSAP-FP cooperation with the MIU, the tricycle operators and drivers, and MRLs); and 3) Comprehensive men and $R H$ approaches that endorse UNFPA's Men and RH model (Davao del Norte and Nueva Vizcaya and TUCP). All of these approaches are viable and the best aspects of each model should be shared to enhance efforts in reaching men.

\section{Community Based Management Information System (CBMIS)}

The community based management information system was developed by the Management Sciences for Health [MSH], 2003). It is carried out quarterly by the Barangay Health Workers [BHW] under the guidance of the local health department staff. This monitoring system is multipurpose by design, having applications for infant and childhood immunization coverage, tetanus toxoid at birth, vitamin A supplementation, and FP.

The CBMIS requires that local health staff at the barangay level maintain accurate records for all households on a quarterly basis. Because the system is multipurpose, many stakeholders are willing to invest in maintaining the system. For FP, CBMIS identifies married women of reproductive age with unmet need under the following categories: those not using any FP method; those who want to use temporary FP methods, and those who specifically want a permanent method (either NSV or BTL). It also identifies women who are using an FP method but are not satisfied with it.

As described above, in Malaybalay, Bukidnon in 2001, IRH worked in partnership with the city health office (CHO), particularly with the nurse in charge of FP, using the CBMIS to identify couples who were not users of any method or are using a calendar method. The nurse was then able to promote the acceptance of SDM by working together with these couples.
In Davao del Norte, in Bago City, and in some areas in Luzon (MSH, 2003), the rural health midwives assisted by BHWs use the CBMIS to identify and recruit acceptors with unmet need for both temporary and permanent FP services. For example, in December 2004 the Bago CHO CBMIS identified 279 married women of reproductive ages (MWRAs) who were not using FP and but who were interested in a temporary method, 80 MWRAs who were interested in BTL, and eight who were interested in NSV. Notably, the system identified 386 MWRAs who are not satisfied with their current FP method. All of these women are referred to the health center for counseling. These management data permit a careful follow-up of priority clients. While the CBMIS system normally focuses on women, more attention to men can result in acceptance of male methods and provide reassurance to men that female methods are safe for their partners.

With CBMIS, FP service providers can identify those who are not satisfied with their current method or who want a permanent method earlier. In areas with quality NSV services, CBMIS has important implications for providing access to NSV. Rather than work with an entire community, community health workers can attend to those with unmet need or who are not satisfied with their method. Using this approach, the MSH has reported that NSV services have increased from 20 a year in 2001 to 200 a year in 2002, and lately they are providing over 2000 men with NSV services annually (MSH, 2003; USAID, 2005). By using CBMIS to identify these men, NSV no longer needs to be a last resort but instead can be an early option.

\section{Social Acceptance Mobilization}

In contrast to the CBMIS approach, the TSAPFP project works with around 40 champions and 100 community influentials, directing efforts at large organizations that are predominantly male, such as tricycle operators and drivers associations, and the MIU. TSAP-FP's cooperation with MRLs has also worked effectively among senior male leadership. 
While the TSAP-FP program is not accountable to USAID for increased FP method use (its chief indicators include favorable attitudes toward FP), it does have an explicit male involvement strategy that emphasizes husbands' acceptance of FP and support to partner's use of FP that is guided by gender equity principles (Interview with TSAP-FP, February 8, 2005).

TSAP-FP programs that work with tricycle drivers and MIU are in the preliminary stage of the campaign and need to focus primarily on FP social mobilization before they can begin initiatives on counseling for FP. Nonetheless, these programs have great potential to reach men with concrete FP services in the future. Because of TSAP-FP's effective work with the Philippine military, a military memorandum will require the provision of FP services.

TSAP-FP's cooperation with NACTODAP has made impressive progress to train Tricycle and Driver Association (TODA) leadership and eventually may develop formal linkages to FP services. However, too much emphasis in the early stages on concrete FP services could be counterproductive as the ground work must first be made with effective communication programs at various levels. While this essential initial work is being done, it is hoped that the TSAP-FP will begin planning for programs to ultimately provide access to service delivery for those people who are persuaded by their FP champions. With the improvement of FP awareness among men, there are opportunities for bringing the services to where the men are: for example, in military camps, in workplaces, and in transportation terminals. There are prospects for ensuring that, together with FP mobilization and social acceptance programs, accessible sources of FP services will be identified; condoms, natural family planning, and NSV will be made available by national and local government agencies, and by private sector groups (USAID, 2005).

\section{Comprehensive Men and RH Approaches}

The UNFPA-assisted TUCP program endorses a comprehensive $\mathrm{RH}$ approach. It addresses FP as part of a wide range of issues, such as violence against women. The project seeks to reduce the cost for men wanting to practice FP by bringing services to where they live or where they are employed. This is illustrated by the successful approach taken by TUCP in getting FP services in the workplace (TUCP, 2005). Similar attempts targeted at working men, their wives or partners are carried out by the Department of Labor and Employment (DOLE), and FP and $\mathrm{MCH}$ Association of Philippine Industries (FPMCHAPI).

TUCP, which has national coverage, provides several broad RH services to adolescents and most working-age men. As noted above in the section on policy, TUCP has made impressive use of collective bargaining agreement to get support for FP services for its workers. However, for male methods of FP, the acceptance was quite low. In fact, there was only one NSV done over the threeyear reporting period. But this in no way diminishes the value of marketing and mobilization efforts carried out by these organizations. The next step to increase the use of male methods is to link reproductive health campaigns to concrete $\mathrm{FP}$ service delivery. IEC and social acceptance campaigns need to be connected to NSV services at local government units and the private sector providers for TUCP members.

Two provinces stand out for their experience in adapting the comprehensive approach to Men and RH. In Nueva Vizcaya, as mentioned above in the section on IEC/BCC, a comprehensive male $\mathrm{RH}$ project is ongoing in about half of the province's municipalities. While the commitment to a comprehensive approach is well documented, it is not clear that the program has had a significant impact on contraceptive use. Using provincial health office data, FP performance was compared between the areas with and without male reproductive health committees. While somewhat higher for new acceptors of condoms, overall FP performance has not increased markedly in areas with MRH Task Forces. This disappointing finding may be due to the fact that, for a high CPR province in a high CPR region, increasing FP use may not have been prioritized in Nueva Vizcaya because it was already high to begin with. 
The province of Davao de Norte is outstanding in its commitment to men and RH. Here, condom use at seven percent is three times the national average. This is reported to be the result of the male FP and reproductive health programs of the province which are driven by a formal policy enforced by Provincial Ordinance 2000-003: “An Ordinance Creating a Male Reproductive Health (MRH) Clinic in All Rural Health Centers in the Province of Davao del Norte." This is also evident in the strong expression support to male FP among the municipal mayors and Municipal Health Officers (MHOs) in Davao del Norte.

\section{NSV Service Delivery}

The assessment focused to NSV services, with a special emphasis on how acceptors are recruited, quality assurance, and financing NSV services. The most successful NSV programs, such as Banlag, a barangey in Bukidnon, appear to have generated a large number of NSV clients through the influence of well-known acceptors who gave testimonies and motivated other villagers to consider NSV. Because many Filipino men opt for NSV due to financial difficulties in supporting additional children, it is important that NSV be provided for free or at little cost. In most of the FP service facilities visited, men were motivated, introduced to satisfied NSV acceptors, and then counseled on NSV with a requirement for informed consent.

Quality patient services include counseling for free and informed choice. Toward this end, the Municipal Health Offices (MHOs) in the different municipalities of Compostela Valley were given training manuals and NSV kits under the MSH LEAD for Health project. Like NSV teams being developed in other areas, NSV surgical competence and confidence in the province is builtup, the capacity to identify unmet need and motivate couples towards NSV is developed, and the support staff and other resources are established. NSV teams are organized around an "anchor" NSV surgeon with the most experience to assure quality of care and provide back-up for any complication that may arise from an NSV procedure.
In Davao del Norte, a pregnancy occurred after an NSV of the male partner. It was believed to be due to a vas deferens that was left intact, which was corrected afterwards by the "anchor surgeon" of the group. This "anchor" system helps the FP program by building up the confidence and competence of less experienced NSV surgeons. In Valencia City, there is a private NSV service provider, who is a surgeon with considerable experience; he assumes the role of "anchor" NSV surgeon. He trains other MHOs and general practitioners to do NSV, and they consult him regarding complications or related concerns. Senior "anchor" NSV surgeons carry out peer training sessions for physicians who want to learn vasectomy techniques. Other members of the NSV team are also trained to inform and motivate clients, provide FP counseling, and maintain quality clinical care.

Most of the NSV services provided have been free or subsidized. Grants and assistance come from USAID cooperating agencies like MSH and from the UNFPA supported agencies that have provided support, such as NSV instruments to local government unit (LGU) health offices and to NSV surgeons. For FriendlyCare, funding for NSV comes mainly from corporate sponsors. Even private individuals support NSV, like the US-based surgeons who formed the No-Scalpel Vasectomy, Inc. that occasionally provides highly subsidized services together with the Sacred Heart Hospital of the Southwestern University in Cebu City. The transportation and actual cost of NSV services may be subsidized, as in the case of Dujali, Davao del Norte. This includes around 400 pesos for supplies/medicines. In Valencia City, the local government also provides funds for the supplies and salaries for most of the NSV service team. The NSV surgeon is given around 500 pesos for each surgery.

PhilHealth is a large fund that has yet to be fully utilized for male FP services. Most male FP services are provided in district hospitals or facilities that are PhilHealth accredited. According to the PhilHealth, there are more than 700 facilities that have been accredited to provide NSV for 
members, most of which do not provide NSV services (Interview with Eduardo Banzon, PhilHealth, February 16, 2005). These healthcare providers may be reimbursed for 3,000 pesos or even more per NSV. While PhilHealth reimbursement for NSV has been available for most hospitals for a long time, primary healthcare facilities, like midwife clinics which refer cases or LGU health centers that perform more of the NSVs, find it difficult to access this fund (USAID Presentation Session, 2005). In many cases these types of facilities, unlike the bigger hospitals, cannot be licensed by the $\mathrm{DOH}$ and therefore cannot be accredited by the PhilHealth because they cannot comply with requirements. Until recently, to get a license to perform NSV, the DOH required that the healthcare facility have an anesthesia machine, defibrillators, and other operating room equipment that are too expensive and not even necessary to assure the quality and outcomes of simple vasectomy procedures. Fortunately, these requirements have recently been relaxed, offering hope that more facilities can be licensed in the near future.

From the PhilHealth side, when an NSV is performed in an accredited facility by an accredited service provider, costs and procedures are itemized and only the allowed expenditures are reimbursed. It would be much easier if PhilHealth could instead reimburse a fixed amount for straightforward procedures like NSV. Simplified requirements and processes would make it easier to get financing and, thus, encourage more NSV services.

The primary source of income for some clinics like the WellFamily Midwife Clinics or the FriendlyCare Clinics is from deliveries and other $\mathrm{MCH}$ services. FP services are also provided but these services generate less income. For most FP services, midwives are more cost-effective service providers than physicians, except for VSC (Interview with FriendlyCare, February 9, 2005). While condom sales volumes may recover the cost for some organizations like the FPOP and DKT, for most FP service providers, NSV has the biggest profit margin. But NSV, like condom use, must be accompanied by demand generation like marketing and IEC campaigns.

Regrettably, FP is not a priority of the current national government and male involvement in FP is not a priority of most NGOs and LGUs (DOH 2002; PNGOC, 2005). As such, there are rarely enough funds to cover the cost of NSV promotion and service delivery. Most of the individuals and organizations met during the assessment feel that with improvement in policy and support for FP there would be higher acceptance of NSV and other FP methods by Filipino men and couples.

In summary, a wide range of promising approaches were identified for providing FP services for men and/or helping men to be more supportive of women using FP. While it is acknowledged that the involvement of men in FP entails more than the use of male methods, this assessment devoted considerable attention to the status of NSV services and couple perceptions regarding NSV. Promising strategies have emerged to systematically expand outreach to men for NSV services. These strategies should be encouraged in the context of informed choice and high quality care. The review of NSV services found CBMIS to be effective in identifying unmet need to reach and recruit men. It also confirmed the importance of assuring quality of FP services, especially for NSV. It identified the need to expand mechanisms for financing male FP Services and commodities.

\section{CONCLUSIONS}

This assessment has identified promising programs for advancing men's involvement in FP throughout the country, a foundation for future work that should be supported. Cultural, behavioral and demographic factors in the Philippines are favorable to efforts to involve men in FP. Data on men's sexual behavior show positive trends: a relatively mature age of first intercourse (18.8) with the vast majority reporting they have been faithful to their partner and have not resorted to commercial sex workers in the past year. Data for young men show substantial FP knowledge and 
use compared to older married men. There is an opportunity to work with young men to encourage continued responsible sexual behavior. Attitudinal variables about men as reported by women, as well as the limited results published for men, suggest that the vast majority of men hold supportive views on family size, FP, and negotiation of condom use within marriage to protect a woman from a husband with an STI. Other favorable factors include the high literacy rate in the Philippines and increasing labor force participation for women (not to mention that the country has a highly favorable social climate for, and a critical mass of organizations active in undertaking social development innovations).

The current status of $\mathrm{MCH}$ service delivery in the Philippines, with the majority of women reporting four or more antenatal visits as well as at least one postnatal visit, may be favorable to replicating a strategy of including men in maternity, as implemented in India within an operations research project carried out by the Population Council Frontiers Program (Frontiers, 2004; NSO ORC Macro, 2004). Given the need to reduce the delay between completion of desired family size and use of permanent methods in the Philippines, working to include men in antenatal and postnatal care, especially for their second and third child, may help to both improve birth outcomes and increase acceptance of effective FP methods.

There are positive factors in the Philippines, but unfavorable conditions restrict efforts to involve men in FP. Important constraints include: the adverse policy climate toward many methods of FP; the extremely low level of use of male methods, combined with the relatively low efficacy and continuation rates of these methods; the high levels of concern about side effects; and the current decrease in donor support for FP commodities.

The potential to expand the use of male methods must be realized. While the recent innovations in providing NSV are promising and warrant expanded donor support, the process of expanding access while maintaining quality care is a major challenge that may take many years. Women as well as men must be convinced that the advantages of NSV outweigh any potential adverse effects. Only a small percentage of women not using FP express interest in condoms in the future; even fewer women express interest in NSV. As part of the life cycle approach to fertility management, the condom seems to be a bridging method for couples who often switch to other methods. The real benefits from involving men in FP will probably be found in increased acceptance, continuation and efficacy of female methods.

It is vital that future efforts to involve men adhere to a gender equitable framework. This will not only lead to good project design, but will reassure women's health advocates that their interests will not be jeopardized. While it may take some time before a comprehensive men and $\mathrm{RH}$ framework is adopted by the DOH, at the provincial level the UNFPA supported framework will no doubt continue to guide work to involve men. The important caveats of "constructive" involvement and working toward a gender transformative approach need to be kept in mind for any projects that are supported in the future.

For many if not most of the men interviewed, economic necessity appears to be the force behind their interest in FP. While men are seeking FP services out of urgent concern for how to provide for additional children, FP is largely promoted for its health benefits for women and children. Some NGO representatives feel that donor agencies are putting too much emphasis on the health benefits of FP and not enough on the self-interest of men as providers for the family. The promotion of gender equity and the health benefits of FP is absolutely essential, but it may not be the most effective entry point to encouraging men to be involved in FP. Serious lost opportunities to involve men in FP will result if programs fail to stress economic issues.

Overall, when working to involve men, there should be a comprehensive approach toward four key groups: 1) young men supportive of and directly involved in FP; 2) adult men supportive of and directly involved in FP; 3) women supportive of involving men in FP; and 4) health providers supportive of involving men in FP. 
When considering the critical aspects of men's involvement in $\mathrm{FP}$ - such as research, policy and guidelines, IEC/BCC strategies, and service delivery-several recommendations should be supported for action (see the complete assessment report for the full set of short- and long-term recommendations) (Clark et al., 2005). For instance, in research, there is a need to rationalize the men and FP research agenda, and strengthen and evaluate the use of research findings in program and projects. It is vital to make greater use of existing data to assess barries and facilitating factors for male support for and use of FP, especially the male module for the 2003 National Demographic and Health Survey. For policy and guidelines, it is crucial to designate and fund an agency with policy experience to systematically support relevant policy guidance initiatives. In IEC/BCC and social mobilization, the social acceptance project strategies, (working with men in the workplace, armed services, and Muslim religious leaders), hold tremendous promise and should be expanded. Culturally familiar local and influential public figures for FP messages should be tapped along with enriching IEC handouts and posters with high quality materials that reflect local culture and language. Finally, in service delivery, it is crucial to ensure that social acceptance mobilization protocols with large agencies (such as trade unions that serve men) include planning to develop links to tangible FP services. If feasible, this should be combined with efforts to adapt CBMIS approaches to identify unmet need among men within the membership of these agencies.

\section{ACKNOWLEDGEMENTS}

This assessment was made possible by the combined efforts and support of a wide range of Philippines Government and non-governmental organizations (NGOs). The assessment team was assisted by staff at the USAID Manila Office of Population Health and Nutrition (OPHN), especially Ms. Carina Stover, Chief; Mr. Ephraim Despabiladeras, Project Management Specialist; and Ms. Jeanette H. Maaño, POPTECH InCountry Logistics Officer. Staff at the Philippines Commission on Population generously developed resource materials incorporated into this report. Staff at the University of San Carlos Office of Population Studies kindly shared unpublished qualitative findings and generated quantitative data tables.

\section{REFERENCES}

Amatya, R., Akhter, H., McMahan, J. (1994). The Effect of husband counseling on NORPLANT Contraceptive acceptablity in Bangladesh. Contraception 50 (3).

AVSC International. (December 1998). Male participation in sexual and reproductive health: New paradigms. Report prepared for the Symposium on October 10-14, 1998, Oaxaca, Mexico (Draft).

Badiane, L. (2005). The Impact of gender, sexuality, and social institutions on sexual behavior and reproductive health among youth in Bohol, Philippines. Unpublished doctoral dissertation. The University of Connecticut, Medical Anthropology.

Barker, G. (2004). How do we know if men have Changed? Promoting and measuring attitude change with young men: Lessons learned from Program H in Latin America. Gender equality and men: Learning from practice, Oxfam GB, Oxford.

Becker, S. (1996). Couples and reproductive health: A review of couple studies. Studies in FP, 27(6).

Bhalerao, V.R., Bhalerao, V.R., Galwankar, M.M., Kowli, S.S., Kumar, R.R., \& Chaturvedi, RM (1984). Contribution of the education of prospective fathers to the success of maternal health care programme. Journal of Postgraduate Medicine 30(1),10-12.

Casterline, J.B., Perez, A.E., \& Biddlecom, A.E. (1997). Factors underlying unmet need for FP in the Philippines. Studies in FP, 28(3). 
Clark, S., Flavier, J., Jimenez, P., Lee, R.B., and Solomon, H. "Assessing the status of male involvement in family planning in the Philippines." Submitted to the United States Agency for International Development/ Philippines, Manila, March 2005 (http:// philippines.usaid.gov/documents/ophn/ male_involve.pdf).

Clark S.D., Brunborg H., Rye S., Svanemyr J., and Austveg B. (February, 1999). Increased participation of men in reproductive health programs: A resource document for the ICPD +5 follow-up process. Paper written for Royal Norwegian Ministry of Foreign Affairs under a contract between the Norwegian Board of Health and DIS/Centre for Partnership in Development, Oslo, Norway.

Cohen, S. I., \& Burger, M. (2000). Partnering: A New approach to sexual and reproductive health. New York: United Nations Population Fund.

Department of Health (DOH). (2002). Men's reproductive health strategic program framework development. Manila, Philippines

Despabiladeras, E. [Unpublished report]. Vasectomy and the Filipino male: A proposed exploratory study that seeks to determine the factors leading to the aacceptance or nonacceptance of vasectomy in the Philippines. Manila, Philippines: De La Salle University.

Ezeh, A., Seroussi, M. \& Raggers, H. (1996). Men's Fertility, Contraceptive Use and Reproductive Preferences. DHS Comparative Studies 18.

Fisek, N., \& Sumbuloglu, K. (1978). The effects of husband and wife education on family planning in rural Turkey. Studies in FP, 9 (10/ 11).

FRONTIERS OR Summary No. 45. (2004). India: Men's involvement in partner's pregnancy yields health benefits. Washington, DC: Population Council.

Greene, M.E., \& Biddlecom, A.E. (2000). Absent and problematic men: Demographic accounts of male reproductive roles. Population and Development Review, 26(1),81-115.
Greene, M. (2003). A framework for men and reproductive health programs. Oral presentation at the reaching men to improve reproductive health for all conference. Dulles, Virginia.

Greene, M.E., Mehta, M., Pulerwitz, J., Wulf, D., Bankole, A., \& Singh, S. (2004). Involving men in reproductive health: Contributions to development. Occasional paper prepared for the United Nations Millennium Project. Washington, D.C.

Interagency Gender Working Group (IGWG). (2002). Men and reproductive health orientation guide. Acomplete training workshop available on CD-ROM in English or Spanish; Population Reference (contact: prborders@prb.org ) Washington, D.C.

Interagency Gender Working Group (IGWG). (2005). Implementation guide on reaching men to improve reproductive and sexual health for all. Available at the following URL www.jhuccp.org/ igwg/.

Jimenez, P., \& Lee, R. (2001). Male sexual risk behavior and HIV/AIDS: A survey in three Philippine cities. Manila: De La Salle University.

Lee, R. B., \& Dodson, P. (1998). Filipino men's involvement in women's health initiatives: Status, challenges and prospects. Manila: Social Development Research Center.

Management Sciences for Health (MSH). (2003). Matching grant program, Department of Health Community-based monitoring and information system. Updates from the field: Best practices.

National Statistics Office (NSO) \& ORC Macro. (2004). Philippines National Demographic and Health Survey 2003. Manila: National Economic Development Authority (NEDA). (2003). Harmonized gender and development guidelines for project development, implementation, monitoring and evaluation. Manila, Philippines.

Perez, A.E. \& Palmore, J. A. (1997). Re-evaluating the unmet need for family planning in the Philippines. Asia-Pacific Population Reports, 10. 
Perez, L. (2000). Perceived husbands' influence on contraceptive use among married women in Metro Cebu. Mahidul University (Unpublished Thesis).

Philippine NGO Council (PNGOC) Forum Document. (2002). Technical assistance to male involvement in reproductive health, 4-5 April 2002: A proposal. Manila, Philippines: PNGOC.

Population Reference Bureau. (2004). Breaking news ground in the Philippines: Opportunities to improve human and and environmental wellbeing. Washington, D.C.: PRB.

Pulerwitz, J., Barker G., \& Segundo, M. (April, 2004). Promoting healthy relationships and HIV/STI prevention for young men: Positive findings from an intervention study in Brazil. Horizons Research Update.

Raymundo, C. \& Cruz, G. (2004). Youth sex and risk behaviors in the Philippines. Quezon City, Philippines: University of the Philippines, Population Institute.
Save the Children. (2003). Walking the extra mile. Project report to the Davin and Lucile packard foundation. Save the children Philippine Field Office, Manila, Philippines.

Terefe, A., \& Larson, C. (1993). Modern contraception use in Ethiopia: Does involving husbands make a difference? American Journal of Public Health, 83(11).

Trade Union Congress of the Philippines (TUCP). (2005).Mobilizing men for involvement in reproductive health in the workplace. Power point presentation.

United Nations Population Fund (UNFPA). (2000). 5th program reproductive health module for nurses. Manila, Philippines: University of the Philippines, College of Public Health and National Institute of Health.

USAID Mission. (2005). Assessing the status of male involvement in FP in the Philippines. Notes from USAID Presentation.

Wang, C. (1998). Reducing pregnancy and induced abortion rates in China: FP with husband participation. American Journal of Public Health, 88 (4). 